\title{
The Influence of Topics on Listening Strategy Use for English for Academic Purposes
}

\author{
Mu-hsuan Chou ${ }^{1}$ \\ ${ }^{1}$ Department of Foreign Language Instruction, Wenzao Ursuline University of Languages, Taiwan \\ Correspondence: Mu-hsuan Chou, Department of Foreign Language Instruction, Wenzao Ursuline University of \\ Languages, Kaohsiung, Taiwan. E-mail: mhchou@gmail.com
}

\author{
Received: October 21, 2014 Accepted: November 27, 2014 Online Published: January 20, 2015 \\ doi:10.5539/elt.v8n2p44 URL: http://dx.doi.org/10.5539/elt.v8n2p44
}

\begin{abstract}
Listening is an essential skill for English as a Foreign Language learners studying in English-speaking universities to succeed in various fields of study. To comprehend subject material and improve listening effectiveness, learners are generally advised to develop strategies which help them process the target language in specific contexts. Therefore, the aim of this study was to investigate what strategies were adopted to listen to general and subject-specific English material. Furthermore, the study examined the process of listening comprehension in relation to the effectiveness of strategy use. The study was carried out with 92 Taiwanese final-year university students taking EAP courses. Questionnaires, listening comprehension questions, and retrospective interviews were used. The results showed that strategy use varied markedly between the two types of listening materials. The effectiveness of certain strategy adoption was influenced by topical familiarity and personal experience.
\end{abstract}

Keywords: listening strategies, English for Academic Purposes, tests, EFL

\section{Introduction}

The last three decades have seen a wealth of research into language learners' strategy use for listening in first (L1), second (L2), and foreign language (FL) settings and how strategy use relates to successful listening comprehension and individual cognitive processing (Macaro, Graham, \& Vanderplank, 2007). One of the most fruitful areas of listening strategy research has been in cognitive nature of listening and listening in communication; however, L2 listening still remains the least researched compared with the other three language skills (Flowerdew \& Miller, 2005; Lynch, 2011; Vandergrift, 2006). In recent years, as English for academic (EAP) and/or specific purposes (ESP) courses has become increasingly prevalent and important in FL contexts at tertiary level where English is used as the language for instruction (Chou, 2011; Chou, 2013; Hyland, 2006), listening to English for academic purposes (EAP), or more specifically, English for general/specific academic purposes (EGAP/ESAP), has been increasingly recognized as essential for university students. While much of linguistic processing (such as recognition of words and syntactic parsing) of first language users is automated, L2 and FL learners, who lack linguistic and content knowledge, need to work out the meaning of words and sentences under the constraints of limited working memory for listening (Færch \& Kasper, 1986; Goh, 2002). For the purposes of enhancing and facilitating learning, there is a general agreement that learner strategies help language learners perform and solve specified tasks (Cohen, 2007; O’Malley, Chamot, \& Küpper, 1989; Oxford, 2011). Therefore, investigation into listening strategy use in a range of foreign language academic contexts helps shed light on how EFL learners process and comprehend the target language with respect to specific topical content.

While coping with tasks in language tests, test-taking strategies are important cognitive skills that can influence students' performance (Dodeen, 2008), and test-taking strategies share the features of language-use strategies in which metacognition and cognition are involved. To date, research on test-taking strategies have mostly been explored with reading comprehension tests using different types of test techniques (Cohen, 1998; Cohen, 2006) or reading materials (Chou, 2013), and test-taking strategies for listening remain relatively under-researched (Field, 2013). As a result, the purposes of the present study were to examine what listening strategies were adopted by EFL university students to comprehend two types of academic English (i.e., EGAP and ESAP) and the effectiveness of strategy use in association with the listening processes in the two contexts. In doing so, this 
study seeks to contribute to our growing understanding of the influence of topics on listening comprehension, strategy use and its effectiveness of listening to EAP materials.

\section{Literature Review}

When learning and listening to an L2 or FL, learners may employ a number of strategies to help them comprehend efficiently in a variety of learning contexts or solve tasks in tests (Chamot, 2005; Cohen, 1998, 2007, 2010; Oxford, 2011). Similar to learning strategies, language use strategies refer to "mental operations or processes that learners consciously select when accomplishing language tasks" (Cohen, 1998, p. 92). Language use strategies also comprise test-taking strategies in which language learners operationalize their basic listening skills, vocabulary knowledge, as well as the related skills of grammar and translation to respond meaningfully to test items and tasks during test-taking processes (Cohen, 2006). According to Cohen (2010), learning strategies and language use strategies (including test-taking strategies) have been categorized in numerous ways, but generally speaking, two major types are metacognitive and cognitive strategies. These strategies involve a large degree of cognitive and metacognitive processing in comprehending the target language and the test items. Metacognitive listening strategies, according to Vandergrift (1997), include planning (e.g., directed attention for main ideas, selective attention for details), monitoring, and evaluation. When answering questions in listening exercises or tests, these strategies are used for managing responses. For example, learners may select options through the elimination of other options, consider or postpone dealing with a question, find answers in the text through same vocabulary or synonyms, or change answers after completing other questions. Cognitive listening strategies, on the other hand, cover making inferences (from language and voice), elaboration (e.g., knowledge of the world or personal experience), translation, summarization, and resourcing (Vandergrift, 1997). Another set of strategies relating to test-taking is test wiseness, which are, according to Cohen (2006, p. 308), "strategies for using knowledge of test formats and other peripheral information to answer test items without going through the expected linguistic and cognitive processes." For example, test-takers may choose an option that seems to deviate from the others or take advantage of clues appearing in other questions or options.

Over the past few decades, research on FL listening strategies has been primarily concerned with the relationship between strategy use and successful listening comprehension (Goh, 1998; Jurkovič, 2010; O'Malley et al., 1989; Osada, 2001; Vandergrift, 1997). Although these studies were carried out with learners of different language backgrounds and widely varying control over linguistic ability level, successful listeners have repeatedly been found to use more metacognitive strategies (like 'elaboration', 'making inferences', and 'self-monitoring') and to activate top-down processing, so that they overcome cognitive constraints during the process of encoding semantic cues in working memory. For example, Shang (2008), comparing the listening strategy use of advanced, intermediate, and beginner level Taiwanese EFL university students, discovered that the advanced listeners tended to combine a range of strategies, while the beginners relied heavily on memory strategies. Another important topic in research on listening strategy use involved using prior knowledge in listening comprehension (e.g., Bonk, 2000) and its relation to task type (Chiang \& Dunkel, 1992; Field, 2004; Tsui \& Fullilove, 1998). It has been discovered that prior knowledge can be an advantage when the learners' lexical ability is sufficient to understand the information in the text and connect it with their knowledge of the text. To enhance listening comprehension, research on strategy-based instruction (SBI) in the listening classroom has increased in recent years (Bommelje, 2012; Graham \& Macaro, 2007; Imhof, 2001; Seo, 2005). The results have shown that SBI can serve as positive reinforcement for developing listening strategy use. Although much work has been done to date, more studies need to be conducted to ascertain listening processes, comprehension, and strategy use for a variety of academic topics in different English learning contexts.

EAP courses can be divided into two main categories: English for general academic purposes (EGAP) and English for specific academic purposes (ESAP) (Jordan, 1997). While the former has been established for the purpose of training university students to develop their listening skills and language use in everyday situations, the latter has focused on comprehending subject-specific materials, such as politics, economics, business, science, technology, environment, health and medicine, crime, or war, where specific terminologies associated with particular domains are used. In Taiwan, English education is compulsory in primary and secondary schools where English is taught for general purposes. The focus of English education has shifted at university level, however, from general English training to learning of subject-specific English. Listening skills have, as a result, become essential for students studying in English. Listening comprehension in EAP contexts involves a complicated set of processes, from decoding and interpreting multi-modal input, to constructing a discourse representation, and monitoring comprehension, all of which place huge cognitive demands on ESL and EFL students (Taylor \& Geranpayeh, 2011). Up to this point, however, there have been few empirical studies of the connection between types of academic topics and the effectiveness of strategy use for listening comprehension in 
EFL contexts. With the increasing popularity of EAP courses in many EFL countries, especially in China and Taiwan, it is worth examining how Taiwanese EFL university students - with Mandarin Chinese as their L1 - process and comprehend EGAP and ESAP topics in listening tests. Students' strategy use for listening to EGAP materials can serve as a benchmark in comparison to their strategy use in ESAP contexts. Within the extensive literature available on academic listening, comparatively little research has focused on the influence of different topics, say general and subject-specific, on EFL undergraduate students' choices of listening strategies and the effectiveness of strategy use in the two contexts. The present study addressed the following two research questions:

1) What strategies were used for listening to English for general and subject-specific academic materials?

2) Which strategies were found the most and least useful for listening to the two types of materials? Why?

\section{Research Method}

Listening strategies are usually elicited via a variety of methods: think-aloud protocols, retrospective verbal reports, interviews, questionnaires, and diaries (Goh, 1998, 2002; Lynch \& Mendelsohn, 2010; Macaro et al., 2007; O'Malley et al., 1989). While think-aloud protocols yield valuable qualitative data, the types and numbers of strategy reported during listening, and researchers' prompting may affect the elicitation process. Retrospective interviews, which require the participants to report their listening and question-answering process immediately after the listening, may not be influenced by the intervention of listening. Questionnaire surveys provide a more comprehensive list of strategies that may be used in listening tests, although the data obtained can be superficial. In-depth and detailed retrospective interview data can help compensate for the limitations of questionnaires. Macaro et al. (2007) accordingly suggest that triangulating multiple methods might provide more reliable data. Cohen, Manion, and Morrison (2011) similarly noted that the multi-method approach provides a more complete view of the complexity of human behaviour and of situation in which human beings interact. Additionally, the multi-method helps overcome the problem of method-boundedness, which comes from using one single research method. Hence, in the present study, questionnaire surveys and retrospective interviews were adopted.

The listening strategies in the questionnaire were adopted and modified from The Comprehension Strategies of Second Language (French) Listeners by Vandergrift (1997) and the test-taking strategies listed in the article The Coming of Age of Research on Test-taking Strategies by Cohen (2006) (Appendix 1). The questionnaires were piloted with a group of students whose language proficiency was similar to that of the target participants. A few modifications of wording were suggested before the formal administration of the questionnaire. The reliability of the questionnaire was .91 by Cronbach's $\alpha$, which was considered adequate for the purposes of the present study.

\subsection{Research Participants}

The study was carried out with 92 Taiwanese university undergraduates from two intact classes who took EAP courses in their final year of study. The participants majored in modern foreign languages (French, German, Spanish, and Japanese) and Communication Arts and were required to take EAP courses throughout their four years of study. The EAP courses in this university integrated the four language skills, so the students agreed to participate in the listening activities as an extra listening practice (in class time) and to answer comprehension questions related to the listening test tasks. The contents of the EAP courses ranged from general topics in everyday life situations, such as friendships, world cultures, social life, movies, or personal interests, to subject-specific issues, including technology, the environment, crime and law, economic issues, health and medicine, and science. The English proficiency level of the participants was at the B1 threshold ${ }^{1}$ (i.e., intermediate) level of the Common European Framework (CEFR).

\subsection{Research Design and Data Collection}

The EAP course was divided into two semesters with 18 weeks in each semester. In the first semester, the participants listened to EGAP topics once a week. The topics selected for the present study were based on the aforementioned topics in the EAP courses to decrease the variables resulting from listening to unrelated topics. During the listening process, the participants took notes on what they heard for the first time before answering ten comprehension questions. Next, the participants listened again and answered the questions. The whole process lasted 15 minutes. In Week 17, retrospective interviews were carried out with the 20 participants who agreed to recall and share how they processed the listening inputs. Before the retrospection, the students listened to an EGAP topic similar to those they had listened to in the past 16 weeks, and then they took notes and told the researcher what they had listened to. Next, they answered ten listening comprehension questions regarding. Afterwards, they chose the most and least useful strategies from the questionnaire items. In the second semester, the data collection procedure for ESAP listening was similar to that of the first semester.The retrospective 
interviews took place in the library discussion rooms, where the surroundings were quiet and comfortable. The participants were asked to report their strategy use immediately after answering all of the test items. The techniques used for both the EGAP and ESAP listening comprehension items in the present study consisted of multiple-choice, one-word short answer, gap filling, and information transfer items, all of which are common techniques for testing listening (Hughes, 2003).

\subsection{Data Analysis}

Because the participants had taken two types of listening tests (EGAP and ESAP), the data were compared using Paired-sample t-tests. SPSS software (v. 20) was used to calculate the t-tests. The participants' retrospective interviews of listening strategy use were transcribed, translated, and codified into similar categories. The translation of interview data was checked by two bilingual students who were proficient in both Mandarin Chinese and English.

\section{Results}

\subsection{Strategies Used for Listening to EGAP and ESAP Materials}

Paired-sample t-tests were conducted to evaluate differences in strategy use for EGAP and ESAP listening. The results showed that the participants paid more attention to the main ideas and details in the EGAP topics (Q1, $M$ $=3.17, S D=.53$; Q2, $M=2.85, S D=.55)$ than the ESAP ones $(\mathrm{Q} 1, M=2.85, S D=.66, t=3.42, p=.001$; Q2, $M=2.63, S D=.64, t=2.35, p=.021)$. The eta squared statistic (.11 and .06$)$ indicated medium effect sizes (Table 1).

Table 1. Paired samples test result of strategies in EGAP and ESAP listening

\begin{tabular}{|c|c|c|c|c|c|c|c|c|}
\hline \multicolumn{2}{|l|}{ Variable } & \multirow{2}{*}{$\begin{array}{c}95 \% \mathrm{CI} \\
.14, .52\end{array}$} & \multirow{2}{*}{$\begin{array}{l}\text { Mean Time } \\
1(\mathrm{SD} 1) \\
3.17(.53)\end{array}$} & \multirow{2}{*}{$\begin{array}{l}\text { Mean Time } \\
2(\mathrm{SD} 2) \\
2.85(.66)\end{array}$} & \multirow{2}{*}{$\begin{array}{l}\text { N1/ } \\
\text { N2 } \\
92\end{array}$} & \multirow{2}{*}{$\frac{t \text {-value }}{3.42}$} & \multirow{2}{*}{$\begin{array}{l}p \text {-value } \\
p=.001\end{array}$} & \multirow{2}{*}{$\begin{array}{l}\text { Effect size (eta } \\
\text { squared) }\end{array}$} \\
\hline Metacognitive & Q1 G\&S & & & & & & & \\
\hline Strategies & Q2 G\&S & $.03, .40$ & $2.85(.55)$ & $2.63(.64)$ & 92 & 2.35 & $\mathrm{p}=.021$ & .06 \\
\hline & Q3 G\&S & $-.08, .29$ & $2.98(.65)$ & $2.87(.54)$ & 92 & 1.17 & $\mathrm{p}=.247$ & .02 \\
\hline & Q4 G\&S & $-.14, .22$ & $2.76(.64)$ & $2.72(.83)$ & 92 & .48 & $\mathrm{p}=.630$ & .00 \\
\hline & Q5 G\&S & $-.42, .02$ & $2.85(.63)$ & $3.04(.78)$ & 92 & -1.77 & $\mathrm{p}=.080$ & .03 \\
\hline & Q6G\&S & $-.25, .20$ & $3.07(.61)$ & $3.09(.78)$ & 92 & -.19 & $\mathrm{p}=.847$ & .00 \\
\hline & Q7G\&S & $-.40, .01$ & $2.48(.62)$ & $2.67(.87)$ & 92 & -1.88 & $\mathrm{p}=.063$ & .04 \\
\hline \multirow{9}{*}{$\begin{array}{l}\text { Cognitive } \\
\text { Strategies }\end{array}$} & Q8G\&S & $-.38, .08$ & $2.57(.65)$ & $2.72(.88)$ & 92 & -1.32 & $\mathrm{p}=.191$ & .02 \\
\hline & Q9G\&S & $-.02, .42$ & $2.98(.65)$ & $2.78(.78)$ & 92 & 1.77 & $\mathrm{p}=.080$ & .03 \\
\hline & Q10G\&S & $-.09, .35$ & $2.67(.70)$ & $2.54(.72)$ & 92 & 1.16 & $\mathrm{p}=.250$ & .01 \\
\hline & Q11G\&S & $-.15, .24$ & $2.70(.69)$ & $2.65(.70)$ & 92 & .45 & $p=.657$ & .00 \\
\hline & Q12 G\&S & $.21, .66$ & $2.89(.67)$ & $2.46(.86)$ & 92 & 3.85 & $\mathrm{P}<.0005$ & .14 \\
\hline & Q13G\&S & $.15, .54$ & $2.76(.60)$ & $2.41(.74)$ & 92 & 3.54 & $\mathrm{p}=.001$ & .12 \\
\hline & Q14G\&S & $-.54,-.03$ & $2.59(.77)$ & $2.87(.83)$ & 92 & -2.23 & $\mathrm{p}=.028$ & .05 \\
\hline & Q15G\&S & $-.60,-.27$ & $2.59(.58)$ & $3.02(.57)$ & 92 & -5.38 & $\mathrm{p}<.0005$ & .24 \\
\hline & Q16G\&S & $.25, .71$ & $2.74(.68)$ & $2.26(.95)$ & 92 & 4.15 & $\mathrm{p}<.0005$ & .16 \\
\hline \multirow{4}{*}{$\begin{array}{l}\text { Test Wiseness } \\
\text { Strategies }\end{array}$} & Q17G\&S & $-.56,-.14$ & $2.91(.59)$ & $3.26(.74)$ & 92 & -3.30 & $\mathrm{p}=.001$ & .11 \\
\hline & Q18G\&S & $-.61,-.22$ & $2.30(.59)$ & $2.72(.80)$ & 92 & -4.27 & $\mathrm{p}<.0005$ & .17 \\
\hline & Q19G\&S & $-.48,-.05$ & $3.13(.54)$ & $3.39(.77)$ & 92 & -2.41 & $\mathrm{p}=.018$ & .06 \\
\hline & Q20 G\&S & $-.63,-.24$ & $2.89(.73)$ & $3.33(.63)$ & 92 & -4.38 & $\mathrm{p}<.0005$ & .17 \\
\hline
\end{tabular}

Note: 'G' means 'EGAP,' 'S' means 'ESAP'. 
In addition, the use of several cognitive strategies varied more markedly between EGAP and ESAP audio-only listening. There were statistically significant decreases in the use of three cognitive strategies:

1) Using mental imagery to create a picture of what was happening (Q12) from EGAP $(M=2.89, S D=.67)$ to ESAP listening topics $(M=2.46, S D=.86), t=3.85, p<.0005$ (two-tailed). The mean score decrease was .43 with a $95 \%$ confidence interval. The eta squared statistic (.14) indicated a large effect size.

2) Making a mental summary of what was heard (Q13) from EGAP $(M=2.76, S D=.60)$ to ESAP listening ( $M=$ $2.41, S D=.74), t=3.54, p=.001$ (two-tailed). The mean score decrease was .35 with a $95 \%$ confidence interval. The eta squared statistic (.12) indicated a medium effect size.

3) Taking notes of key words or information as participants followed the spoken texts (Q16) from EGAP ( $M=$ $2.74, S D=.68)$ to ESAP listening $(M=2.26, S D=.95), t=4.15, p<.0005$ (two-tailed). The mean score decrease was .48 with a $95 \%$ confidence interval. The eta squared statistic (.16) indicated a large effect size.

The participants found it harder to make mental connections between what they heard and what they imagined in ESAP contexts, possibly due to lack of vocabulary knowledge. On the other hand, the participants resorted to the knowledge in their primary language, in this case Chinese, for help more frequently in the ESAP than the EGAP listening. In addition, different types of listening topics also influenced the strategies the participants used to answer the test items. There were statistically significant increases in the use of two cognitive (Q14 and Q15) and all test wiseness strategies (Q17 to Q20):

1) Translating what was heard in English to Chinese verbatim (Q14) from EGAP $(M=2.59, S D=.77)$ to ESAP listening $(M=2.87, S D=.83), t=-2.23, p=.028$ (two-tailed). The mean score increase was .28 with a $95 \%$ confidence interval. The eta squared statistic (.05) indicated a small effect size.

2) Using knowledge about Chinese to facilitate listening to English (Q15) from EGAP $(M=2.59, S D=.58)$ to ESAP listening $(M=3.02, S D=.57), t=-5.38, p<.0005$ (two-tailed). The mean score increase was .43 with a $95 \%$ confidence interval. The eta squared statistic (.24) indicated a large effect size.

3) Answering the questions in chronological order (Q17) from EGAP $(M=2.91, S D=.59)$ to ESAP listening ( $M$ $=3.26, S D=.74), t=-3.30, p=.001$ (two-tailed). The mean score increase was .35 with a $95 \%$ confidence interval. The eta squared statistic (.11) indicated a medium effect size.

4) Choosing an option that seemed to deviate from the others (Q18), from EGAP $(M=2.30, S D=.59)$ to ESAP listening $(M=2.72, S D=.80), t=-4.27, p<.0005$ (two-tailed). The mean score increase was .42 with a $95 \%$ confidence interval. The eta squared statistic (.17) indicated a large effect size.

5) Selecting the option because it appeared to have a word or phrase (Q19), from the listening text from EGAP $(M=3.13, S D=.54)$ to ESAP listening $(M=3.39, S D=.77), t=-2.41, p=.018$ (two-tailed). The mean score increase was .26 with a $95 \%$ confidence interval. The eta squared statistic (.06) indicated a medium effect size.

6) Selecting the option because it had a word or phrase that appeared in the question (Q20), from EGAP (M= $2.89, S D=.73)$ to ESAP listening $(M=3.33, S D=.63), t=-4.38, p<.0005$ (two-tailed). The mean score increase was .44 with a $95 \%$ confidence interval. The eta squared statistic (.17) indicated a large effect size.

\subsection{The Most and Least Useful Strategies for Listening to the Two Types of Materials}

The interviewees considered the strategies of listening in terms of key ideas, using imagination, making inferences from personal experiences, world knowledge, and knowledge about Chinese, guessing from the tone of voice, making a mental summary, and utilizing the options from other test items very practical in EGAP listening. On the other hand, metacognitive strategies including paying attention to how much listeners understood the listening task, making decisions as to whether the words they heard were right in the context, and cognitive strategies such as translation, and taking notes were viewed as the least helpful strategies in EGAP listening. One possible explanation was that, owing to our limited working-memory capacity, the words and sentences processed during listening are quickly forgotten, and only a few key lexical items will remain in long-term memory (Rost, 2011). Using these strategies requires a longer time to obtain resources, organize, coordinate, monitor, and evaluate the whole set of information, so they were simply considered ineffective, possibly placing a burden on the part of the EFL listeners when they needed to decode the incoming information efficiently. The following excerpts illustrated the effectiveness of strategy use in the EGAP listening:

For me the most useful strategy in listening [EGAP topics] was using prior personal experiences or world knowledge to comprehend the task. Making decisions as to whether the words I heard were right in the context was not helpful. Since I was listening at that moment, all I hope was to understand it. I didn't have time to care whether or not the context matched the words I heard. (Participant 11; translation) 
Listening to main ideas was the most helpful strategy. Translation or taking notes of key words were not effective. I'd rather answer the test items quickly than spend time taking notes. (Participant 19; translation)

I think imagining the listening scenes facilitated me in understanding the contexts, because I'd imagine the facial expressions or emotion of the interlocutors that could help me deduce the answers. But, translating English into Chinese was useless, because it slowed down my listening process. I'd probably forget what was said. (Participant 20; translation)

Nevertheless, guessing by the tone of voice and using imagination in ESAP listening was not found particularly effective. The students did not think the stress or the intonation in the ESAP spoken language was noticeable because the topics were academic, and the tone of the language seemed to be strict and descriptive in nature. Additionally, due to the limited size of their subject-specific vocabulary, it was difficult for participants to imagine the listening scene. Compared with EGAP listening, the participants struggled more at the phonetic and lexical level, trying hard to comprehend and make inferences from uncertain vocabulary and their existing schemata in ESAP listening. Rost (2011, p. 132) notes that L2 listeners have to decode incoming speech that they might perceive as "degraded phonetic quality due to assimilation, prosodic patterns disguising unstressed words and varying speed of input." Even though the learners had learned particular words, it does not necessarily mean they can recognize them in connected speech (Field, 2011; Vandergrift \& Goh, 2009).Listening to main ideas, taking notes of key words or information, and test-wiseness strategies such as choosing an option that seemed to deviate from the others were regarded as more effective strategies in ESAP listening. The interview data agreed well with comparisons between EGAP and ESAP questionnaire findings (Table 1) where these reported effective strategies were used more frequently in ESAP listening, except for the note-taking and translation strategies. The note-taking strategy was reported effective by some participants. It appeared that the effectiveness of using this strategy was associated with individual listening experience. The translation strategy, though adopted more frequently in the ESAP listening in the questionnaire survey, was not considered useful. As the excerpt showed:

It was useless to translate English from Chinese, because it wasted too much time and disturbed my processing of listening content. I'd try to read through the questions or options in the test items and pay more attention to key vocabulary in listening. I'd delete impossible options or guess listening content via key words. (Participant 18 ; translation)

Although listening and reading are both 'receptive' skills, the strategies the EFL learners used to cope with subject-specific texts were different. In the present listening study, test wiseness strategies were more frequently adopted by the participants. In the case of taking ESAP reading tests, nevertheless, similar EFL undergraduate learners tended to resort to metacognitive strategies more frequently (Chou, 2013). Unlike with reading tests, one student specifically indicated that taking listening tests required them to catch known words heard in the fast and transient speech and make judgments or inferences based on them making it impossible to remember or review the whole sentences. Interestingly, the interviewees held opposite opinions towards using strategies to guess the meaning of unknown words by linking them to known words and to make inferences from personal experiences. For example:

Imagining the listening scenes was not helpful. Because I was not familiar with subject-specific vocabulary, I could only guess the meaning of unknown words by linking them to the words I knew, but I was very uncertain about the words I guessed. So it was like patching together all the words and sentences in a mess. I think listening to main ideas, paying attention to keywords, and making inferences based on my own experience would be more practical. (Participant 5; translation)

I tended to find the answers from words or options in other questions. If I couldn't understand, I could still guess the information from the test items. I didn't think using personal experiences was helpful, since I wasn't usually involved in the subject-specific fields, and I didn't have many relevant experiences. (Participant 9; translation)

Table 2 summarized the most and least effective strategies reported by the interviewees. To conclude, topical familiarity influenced how listening was processed and what strategies were adopted to decode linguistic, semantic, and pragmatic meaning, and determined what strategies were effective in facilitating comprehension. In comparison to ESAP listening, the listening strategies for EGAP topics were used in a more various, frequent, and effective way. The effectiveness of certain strategy used in ESAP listening, on the other hand, depended more on individual experiences and one's familiarity with the topics. 
Table 2. Summary of the most and least helpful strategies for EGAP and ESAP listening

\begin{tabular}{|c|c|c|}
\hline & Most helpful & Least helpful \\
\hline EGAP & $\begin{array}{l}\text { - Listening to main ideas } \\
\text { - Using imagination } \\
\text { - Making inferences from personal experiences } \\
\text { and world knowledge } \\
\text { - Knowledge about chinese } \\
\text { - Guessing from the tone of voice } \\
\text { - Making a mental summary } \\
\text { - Using the options from test items }\end{array}$ & $\begin{array}{l}\text { - Paying attention to how much listeners } \\
\text { understood the listening task, } \\
\text { - Making decisions as to whether the words they } \\
\text { heard were right in the context } \\
\text { - Translation } \\
\text { - Taking notes }\end{array}$ \\
\hline ESAP & $\begin{array}{l}\text { - Listening to main ideas } \\
\text { - Taking notes of key words or information } \\
\text { - Test wiseness strategies such as choosing an } \\
\text { option that seemed to deviate from the others }\end{array}$ & $\begin{array}{l}\text { - Guessing by the tone of voice } \\
\text { - Using imagination } \\
\text { - Translation }\end{array}$ \\
\hline
\end{tabular}

\section{Discussion and Implications}

With the increasing prevalence of ESAP courses in universities where English is used as a medium of instruction, listening strategies have become essential for EFL learners to manage a variety of subject-specific topics. However, misinterpretation of content occurs when the lack of vocabulary and schemata fails to provide correct connections between linguistic and non-linguistic contexts during language processing. Accessing schemata can be influenced by a number of factors, such as the relative importance to one's value system and subject familiarity, and can be interrelated and cross-referenced in a variety of ways (Churchland, 1999; Rost, 2011). For example, the data from the questionnaire and interviews showed that certain strategies relating to accessing schemata, such as using one's imagination, making inferences, drawing on knowledge about Chinese, guessing by the tone of voice, and making a mental summary, were considered more effective strategies in understanding familiar, say EGAP, than unfamiliar ESAP topics. Test wiseness strategies, on the other hand, were used more frequently to compensate for listeners' inability to recognize unfamiliar vocabulary and accessibility of schemata in the ESAP listening. To help EFL learners attune to subject-specific topics, a number of studies have shown the advantages of using video-mediated materials in class to increase higher content validity and to facilitate listening comprehension in EAP settings (e.g., Kashani, Sajjadi, Sohrabi, \& Younespour, 2011; Lynch, 2011; Mac Donald et al., 2000; Sueyoshi \& Hardison, 2005). Additionally, Coyle, Hood, and Marsh (2010) and Rost (2011) suggest that learning of and through the target language should take place in an environment that provides learners with comprehensible inputs, such as warm-up brainstorming activities with familiar content and vocabulary, to help them activate prior knowledge before moving on to subject-specific topics. Nonetheless, in the study of testing the listening sections of the TOEIC to Taiwanese EFL learners, Chang and Read (2006) discovered that vocabulary instruction was the least effective support method for listening comprehension, while the provision of background knowledge and repetition of inputs were the most effective. Vocabulary instruction is likely to fail because listening comprehension not only involves becoming familiar with the pronunciation of new or learned words but also adapting to phonetic features, prosodic patterns, and pacing in different spoken contexts. When opportunities to practice and familiarize oneself with the newly learned vocabulary are not sufficient, introducing subject-specific words before listening may not have the intended effect on the EFL learners. In addition, although repetition of listening inputs was found particularly beneficial to listening in the case of EFL learners (Chang \& Read, 2006; Sakai, 2009), Sakai notes that this should be limited to the situation in which learners possess sufficient target language ability to understand the lexis in the listening passages. Flowerdew and Miller (2005) suggest that exercises should be given via an integrated approach to develop critical listening skills. The integrated approach included a discrete-item-based approach for practicing the sounds of words, a grammar-based approach to comprehend sentences, a task-based approach when all of the exercises revolve around a similar topic, and a strategy-based approach to ask students to reflect on how they listen.

What differentiates the difficulty of a topic lies not only in the choice of lexis in the listening texts but also in the complexity of the content, which Brown (1995) called the intrinsic cognitive difficulty. Brown proposed that the 
degree of complexity of the relationship between the interlocutors, the order of events, the familiarity of topics, and the presentation of information in the listening texts dominate the cognitive load of listeners. Processing the information involves mapping words on to grammatical, contextual, and communicative concepts (Nation, 2006) However, when the topics are less familiar to language learners, it is highly unlikely they will access these mental lexicons successfully. Furthermore, one potential problem of the acquisition of lexis in L1 and the target language is the possibility of lexical transfer between two related languages. In the present study, unfortunately, the participants' first language, Chinese does not share a close etymological origin with English. It would thus take a longer time for the Chinese participants to transfer and process the new words. Ellis (2006) considers frequency of input an important factor of the quality and speed of processing listening, in the sense that frequent exposure to new words of various types of subject-specific text, listening, reading, and interaction are the means of learning lexis in a foreign language. Nation (2008), and Tseng and Schmitt (2008) support the idea that accessing vocabulary can be improved through frequency-based practice in coping with affixed forms and recognizing words, as well as utilizing metacognitive strategies to monitor one's listening processes.

\section{Conclusion}

The present study was carried out with 92 Taiwanese final-year university students taking an EAP course, including both EGAP and ESAP topics. While earlier research regarding listening strategies has focused on strategy use and successful listening, the influence of background knowledge in listening comprehension, strategy use differences between L1 and L2 listening, and the SBI (Bommelje, 2012; Bonk, 2000; Goh, 1998; Imhof, 2001; Jurkovič, 2010; Osada, 2001; Seo, 2005; Vandergrift, 1997), the present study took a closer look at what listening strategies were used, what strategies were effective and ineffective, and how listening was processed to comprehend different types of materials in an EFL context.

Listening to EGAP and ESAP materials involved a different degree of strategy adoption to facilitate the process of word recognition and the efficient mapping of words, grammar, schemata, and contexts. While strategies were used in a versatile and flexible manner in EGAP listening, the lack of relevant language and topical knowledge limited the cognitive processing in comprehending subject-specific contents. As a result, Vandergrift and Goh (2009) suggest that listening instruction should focus on a bottom-up approach to reinforce the lexicon in subject-specific domains to help learners reduce the problem of word segmentation and recognition in a rhythmically different language and only later move on to a top-down approach that helps train listening to a higher-order of metacognitive process involving organizing, monitoring, and reflecting linguistic and non-linguistic information.

Although the present study has yielded findings that have both theoretical and pedagogical implications, its design is not without flaws. First, the generalizability of the results to another EFL population may be limited. Additionally, the participants' language proficiency and cultural background can influence their choices of strategy use and language processing. Other limitations involve using different types of tasks, groups of language learners with different cultural backgrounds, and that successful and unsuccessful listeners clearly need further exploration. Despite the limitations, the results of this study provide evidence on which listening strategies were used to comprehend general and subject-specific topics in an EAP setting, thus shedding light on the effectiveness of strategy adoption, and have implications for teaching ESAP listening to EFL learners with intermediate English proficiency.

\section{References}

Bommelje, R. (2012). The listening circle: Using the SBI model to enhance peer feedback. International Journal of Listening, 26(2), 67-70. http://dx.doi.org/10.1080/10904018.2012.677667

Bonk, W. J. (2000). Second language lexical knowledge and listening comprehension. International Journal of Listening, 14, 14-31. http://dx.doi.org/10.1080/10904018.2000.10499033

Brown, G. (1995). Speakers, listeners and communication: Explorations in discourse analysis. Cambridge, UK: Cambridge University Press.

Chou, M.-H. (2011). The influence of learner strategies on oral presentations: A comparison between group and individual performance. English for Specific Purposes, 30(4), 272-285. http://dx.doi.org/10.1016/j.esp. 2011.04.003

Chou, M.-H. (2013). Strategy use for reading English for general and specific academic purposes in testing and nontestingcontexts. Reading Research Quarterly, 48(2), 175-194. http://dx.doi.org/10.1002/rrq.42

Churchland, P. M. (1999). Learning and conceptual change: The view from the neurons. In A. Clark, \& P. Millican (Eds.), Connectionism, concepts and folk psychology (pp. 7-44). Oxford: Oxford University Press. 
Cohen, A. D. (1998). Strategies and processes in test taking and SLA. In L. F. Bachman, \& A. D. Cohen (Eds.), Interfaces between secondlanguage acquisition and language testing research (pp. 90-111). Cambridge, UK: Cambridge University Press.

Cohen, A. D. (2006). The coming of age of research on test-takingstrategies. Language Assessment Quarterly, 3(4), 307-331. http://dx.doi.org/10.1080/15434300701333129

Cohen, A. D. (2007). Coming to terms with language learner strategies: Surveying the experts. In A. D. Cohen, \& E. Macaro (Eds.), Language learner strategies (pp. 29-45). Oxford: Oxford University Press.

Cohen, A. D. (2010). Focus on the language learners: Styles, strategies and motivation. In N. Schmitt (Ed.), An introduction to applied linguistics (pp. 161-178). London, UK: Hodder \& Stoughton Ltd.

Cohen, L., Manion, L., \& Morrison, K. (2011). Research methods in education (7th ed.). Oxon, UK: Routledge.

Coyle, D., Hood, P., \& Marsh, D. (2010). Content and language integrated learning. Cambridge, UK: Cambridge University Press.

Dodeen, H. (2008). Assessing test-taking strategies of university students: developing a scale and estimating its psychometric indices. Assessment and Evaluation in Higher Education, 33(4), 409-419. http://dx.doi.org/10.1080/02602930701562874

Ellis, R. (2006). The methodology of task-based teaching. Asian EFL Journal, 8(1), 19-45.

Færch, C., \& Kasper, G. (1986). The role of comprehension in second language learning. Applied Linguistics, 7(3), 257-274. http://dx.doi.org/10.1093/applin/7.3.257

Feak, C. B., \& Salehzadeh, J. (2001). Challenges and issues in developing an EAP video listening placement assessment: A view from one program. English for Specific Purposes, 20(S1), $477-493$. http://dx.doi.org/10.1016/S0889-4906(01)00021-7

Field, J. (2008). Listening in the language classroom. Cambridge, UK: Cambridge University Press.

Field, J. (2011). Into the mind of the academic listener. Journal of English for Academic Purposes, 10(2), 102-112. http://dx.doi.org/10.1016/j.jeap.2011.04.002

Field, J. (2013). Cognitive validity. In A. Geranpayeh, \& L. Taylor (Eds.), Examining listening (pp. 77-151). Cambridge, UK: Cambridge University Press.

Flowerdew, J., \& Miller, L. (2005). Second language listening: Theory and practice. Cambridge, UK: Cambridge University Press.

Goh, C. C. M. (1998). How ESL learners with different listening abilities use comprehension strategies and tactics. Language Teaching Research, 2(2), 124-147. http://dx.doi.org/10.1177/136216889800200203

Goh, C. C. M. (2002). Exploring listening comprehension tactics and their interaction patterns. System, 30(2), 185-206. http://dx.doi.org/10.1016/S0346-251X(02)00004-0

Graham, S., \& Macaro, E. (2007). Designing Year 12 strategy training in listening and writing: From theory to practice. Language Learning Journal, 35(2), 153-173. http://dx.doi.org/10.1080/09571730701599203

Hood, S., \& Forey, G. (2005). Introducing a conference paper: Getting interpersonal with your audience. Journal of English for Academic Purposes, 4(4), 291-306. http://dx.doi.org/10.1016/j.jeap.2005.07.003

Hughes, A. (2003). Testing for language teachers (2nd ed.). Cambridge, UK: Cambridge University Press.

Hyland, K. (2006). English for academic purposes: An advanced resource book. Oxon, UK: Routledge.

Imhof, M. (2001). How to listening more effectively: Self-monitoring strategies in listening. International Journal of Listening, 15(1), 2-19. http://dx.doi.org/10.1080/10904018.2001.10499042

Jordan, R. R. (1997). English for academic purposes: A guide and resource book for teachers. Cambridge, UK: Cambridge University Press.

Jung, E. H. (2006). Misunderstanding of academic monologues by nonnative speakers of English. Journal of Pragmatics, 38(11), 1928-1942. http://dx.doi.org/10.1016/j.pragma.2005.05.001

Jurkovič, V. (2010). Language learner strategies and linguistic competence as factors affecting achievement test scores in English for Specific Purposes. TESOL Journal, 1(4), 449-469. http://dx.doi.org/10.5054/tj.2010. 234765

Kashani, A. S., Sajjadi, S., Sohrabi, M. R., \& Younespour, S. (2011). Optimizing visually-assisted listening 
comprehension. Language Learning Journal, 39(1), 75-84. http://dx.doi.org/10.1080/09571730903545236

Language Training and Testing Center. (2013). Conversion table of CEFR, GEPT, FLPT, and CSEPT. Retrieved February 22, 2014, from http://www.lttc.ntu.edu.tw/Tests_developed_by_LTTC.pdf

Lynch, T. (2011). Academic listening in the 21st century: Reviewing a decade of research. Journal of English for Academic Purposes, 10(2), 79-88. http://dx.doi.org/10.1016/j.jeap.2011.03.001

Lynch, T., \& Mendelsohn, D. (2010). Listening. In N. Schmitt (Ed.), An introduction to applied linguistics (2nd ed., pp. 180-196). London, UK: Hodder Education.

Macaro, E., Graham, S., \& Vanderplank, R. (2007). A review of listening strategies: Focus on sources of knowledge and on success. In A. D. Cohen, \& E. Macaro (Eds.), Language learner strategies (pp. 165-185). Oxford: Oxford University Press.

MacDonald, M., Badger, R., \& White, G. (2000). The real thing? Authenticity and academic listening. English for Specific Purposes, 19(3), 253-267. http://dx.doi.org/10.1016/S0889-4906(98)00028-3

Nation, P. (2006). Vocabulary: Second language. In K. Brown (Ed.), Encyclopedia of language and linguistics (2nd ed., pp. 448-454). Oxford: Elsevier.

Nation, P. (2008). Teaching vocabulary: Strategies and techniques. Boston: Heinle Cengage Learning.

O’Malley, J. A., Chamot, A. U., \& Küpper, L. (1989). Listening comprehension strategies in second language acquisition. Applied Linguistics, 10(4), 418-437. http://dx.doi.org/10.1093/applin/10.4.418

Osada, N. (2001). What strategy do less proficient learners employ in listening comprehension? A reappraisal of bottom-up and top-down processing. Pan-Pacific Association of Applied Linguistics, 5(1), 73-90.

Oxford, R. L. (2011). Teaching and researching language learning strategies. Harlow, UK: Pearson Education Limited.

Rost, M. (2011). Teaching and researching listening (2nd ed.). Harlow, UK: Pearson Education Limited.

Sakai, H. (2009). Effect of repetition of exposure and proficiency level in L2 listening tests. TESOL Quarterly, 43(2), 360-372. http://dx.doi.org/10.1002/j.1545-7249.2009.tb00179.x

Seo, K. (2005). Development of a listening strategy intervention program for adult learners of Japanese. International Journal of Listening, 19(1), 63-78. http://dx.doi.org/10.1080/10904018.2005.10499075

Shang, H.-F. (2008). Listening strategy use and linguistic patterns in listening comprehension by EFL learners. International Journal of Listening, 22(1), 29-45. http://dx.doi.org/10.1080/10904010701802147

Sueyoshi, A., \& Hardison, D. M. (2005). The role of gestures and facial cues in second-language listening comprehension. Language Learning, 55(4), 661-699. http://dx.doi.org/10.1111/j.0023-8333.2005.00320.x

Taylor, L., \& Geranpayeh, A. (2011). Assessing listening for academic purposes: Defining and operationalizing the test construct. Journal of English for Academic Purposes, 10(2), 89-101. http://dx.doi.org/10.1016/j.jeap.2011.03.002

Tseng, W., \& Schmitt, N. (2008). Toward a model of motivated vocabulary learning: A structural equation modeling approach. Language Learning, 58(2), 357-400. http://dx.doi.org/10.1111/j.1467-9922.2008.0044 4.x

Vandergrift, L. (1997). The comprehension strategies of second language (French) listeners: A descriptive study. Foreign Language Annals, 30(3), 387-409. http://dx.doi.org/10.1111/j.1944-9720.1997.tb02362.x

Vandergrift, L. (2006). Second language listening: Listening ability or language proficiency? Modern Language Journal, 90(1), 6-18. http://dx.doi.org/10.1111/j.1540-4781.2006.00381.x

Vandergrift, L., \& Goh, C. (2009). Teaching and testing listening comprehension. In M. H. Long, \& C. J. Doughty (Eds.), The handbook of language teaching (pp. 395-411). Chichester, UK: Blackwell Publishing Ltd.

\section{Note}

Note 1. In the present study, the CEFR B1 threshold level of the participants' English proficiency was based on their test scores of the General English Proficiency Test (GEPT), which they had taken and passed at Intermediate level in 2014. Because the GEPT test was developed based on the CEFR, the conversion table of CEFR and GEPT showed that GEPT Intermediate level is equal to the CEFR's B1 threshold level (LTTC, 2014). 


\section{Appendix 1}

Questionnaire of Listening Strategy Use for EGAP and ESAP Listening

$1=$ Strongly disagree $\quad 2=$ Disagree $\quad 3=$ Agree $\quad 4=$ Strongly agree

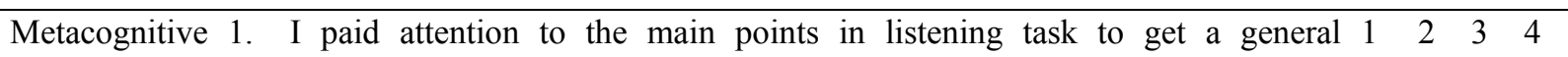
strategies understanding of what is said.

2. I paid attention to details in the listening task. $\quad 1 \quad 2 \quad 3 \quad 4$

3. I paid attention to how much I understood the listening task. $\quad 1 \quad 2 \quad 3 \quad 4$

4. I made decisions as to whether the words I heard were right in the context. $\quad \begin{array}{lllll}1 & 2 & 3 & 4\end{array}$

5. I skipped the parts I didn't know and completed the task. $\quad 1 \quad 2 \quad 3 \quad 4$

6. I used the process of elimination. $\quad 1 \quad \begin{array}{llll}1 & 3 & 4\end{array}$

7. I changed my responses as appropriate. $\quad \begin{array}{llll}1 & 2 & 3 & 4\end{array}$

\begin{tabular}{llllllll}
\hline Cognitive & 8. & I guessed the meaning of unknown words by linking them to known words. & 1 & 2 & 3 & 4
\end{tabular}

strategies 9 . I guessed by means of the tone of voice. $\quad 1 \begin{array}{lllll}2 & 3 & 4\end{array}$

10. I used prior personal experience to comprehend the task. $\quad 1 \quad 2 \quad 3 \quad 4$

11. I used my world knowledge to comprehend the task. $\quad 1 \quad 2 \quad 3 \quad 4$

12. I used mental imagery to create a picture of what was happening. $\quad \begin{array}{lllll}1 & 2 & 3 & 4\end{array}$

13. I made a mental summary of what I heard. $\quad \begin{array}{llll}1 & 2 & 3 & 4\end{array}$

14. I translated what I heard in the foreign language (i.e., English) to my first $\begin{array}{llllll}1 & 2 & 3 & 4\end{array}$ language (i.e., Chinese) verbatim.

15. I used knowledge about Chinese to facilitate listening to English. $\quad \begin{array}{llll}1 & 2 & 3 & 4\end{array}$

16. I took notes of key words or information as I followed the spoken texts. $\quad \begin{array}{lllll}1 & 2 & 3 & 4\end{array}$

\begin{tabular}{lllllll}
\hline Test wiseness 17. I answered the questions in chronological order in the listening. & 1 & 2 & 3 & 4
\end{tabular}

strategies 18 . I chose an option that seemed to deviate from the others, was special, was $\begin{array}{lllll}1 & 2 & 3 & 4\end{array}$ different, or conspicuous.

19. I selected the option because it appeared to have a word or phrase from the $\begin{array}{lllll}1 & 2 & 3 & 4\end{array}$ listening text - possibly a key word.

20. I selected the option because it had a word or phrase that appeared in the $\begin{array}{llll}1 & 2 & 3 & 4\end{array}$ question.

\section{Copyrights}

Copyright for this article is retained by the author(s), with first publication rights granted to the journal.

This is an open-access article distributed under the terms and conditions of the Creative Commons Attribution license (http://creativecommons.org/licenses/by/3.0/). 